\title{
Further Understanding of Metabolic Processes for Crop Improvement - An Integrated Approach with Reference to Deprived and Developed Countries
}

\author{
Adhikarla Suryanarayana Rao \\ Department of Biotechnology, Bharathidasan University, Tiruchirappalli, India \\ Email address: \\ asraobio@gmail.com

\section{To cite this article:} \\ Adhikarla Suryanarayana Rao. Further Understanding of Metabolic Processes for Crop Improvement - An Integrated Approach with \\ Reference to Deprived and Developed Countries. Plant. Vol. 8, No. 2, 2020, pp. 17-30. doi: 10.11648/j.plant.20200802.11
}

Received: May 6, 2020; Accepted: May 21, 2020; Published: June 17, 2020

\begin{abstract}
Food deficiency, particularly protein-calorie malnutrition is a concern in many countries in Africa and Asia. An exhaustive survey of recent research efforts to alleviate the problem has been made. A due appraisal of the existing information has been given. Appraisal and critical analysis of the existing information has been discussed with reference to: techniques and methodology employed to understand and manipulate metabolism; inter-relationships between different nutrient sources, translocation of water and nutrients and utilization by different sinks; biochemical composition of seeds; seed storage protein fractions; amino acid deficiencies and human nutrition; inorganic nitrogen assimilation; symbiotic biological nitrogen fixation; ammonia assimilation; amide versus ureide transport; composition of xylem and phloem saps; biochemical changes during leaf senescence; metabolic reworking of amino acids; cell division and cell expansion during seed development; determinate and indeterminate cultivars; crop performance under varying cultural and environmental conditions; harvest index; yield compensatory mechanisms; combining conventional and modern approaches and complementation of agriculture with animal husbandry. Based on the existing data, possible ways of future planning have been highlighted. Need for public and national awareness has been emphasized with respect to assessing priorities of nutritional needs; resorting to complementary/supplementary food items; recommended daily dietary requirements; increased utilization of land towards agriculture and /or animal husbandry and the need for international aid.
\end{abstract}

Keywords: Malnutrition, Nitrogen Metabolism, Biological Nitrogen Fixation, Seed Storage Proteins, Genetic Engineering, Future Planning, Public Awareness

\section{Background}

For rational and successful improvement, in addition to the existing knowledge and approaches, additional knowledge and lateral thinking of metabolic processes of source - translocation-sink and their inter-relationships in the crops and biochemical changes during seed development -in all the parts of the plantis needed to increase seed yield and /or quality either by conventional or modern molecular approaches, for the ultimate purpose of human and live stock consumption, food processing and other industrial applications $[1,9,22,26,27,29,34,35,44$, $48,51,53,55,56,65,74,80,83,84]$.

Almost invariably, all research articles pertaining to crop improvement mention the pressure to increase yield and protein content and quality because of the a) present huge population b) future projections of population growth and c) plight of the poor in some developing countries particularly in Africa and Asia. Often ProteinCalorie malnutrition is highlighted in these places. In spite of Green revolution increasing food production a lot, the pressure continues ! It is a challenge and a responsibility of not only scientists but also other social custodians to nullify this pressure $[30,47,90,95]$.

\section{What We Know Already About the Mentioned Goals-Some Salient Points}

\subsection{Crops Investigated}

Scientists have been working primarily with different 
cereals, legumes, oil seeds and root crops. Some additional crops also are investigated. Arabidopsis and tobacco like in so many other cases were used as model organisms in addition to the staple crops for molecular biology and biotechnology intervention. Cereals are supposed to contribute more than $50 \%$ of the global requirements of calories and in some regions it can reach even $70 \%$ and contributes to more than $35 \%$ of protein globally. Among them three crops rice, wheat and maize contribute the most. Next to cereals come the legumes in global importance. In view of the above the cereals rice, wheat and maize are the more investigated. Among the legumes, Chickpea, Pigeonpea, Field pea, Cowpea, Soybean, Groundnut, Vetch, different Clovers and other different beans like Lupins, Lentils, Kidney bean, Navy beans, Black beans, Pinto bean etc have also been investigated in considerable details. Oil seeds studied were Brassica, Castor, Sunflower, Safflower, Sesame, Cotton. Soybean and Groundnut have been studied extensively as they are considered both as legumes and oil seeds. However, the researches have applicability to all crops even to those which are yet to be studied. Findings in one crop can help in the manipulation of processes of other crops in the same category or crops in other categories $[2,12,19$, $24,27,29,37,39,50,53,59,77,86,88]$.

\subsection{Variation in Seed and Storage Protein Composition}

Storage proteins of the above mentioned crops have been investigated keeping in view their importance for humans and livestock consumption, food processing and other industrial applications. Comparing the protein contents, storage protein fractions and their amino acid composition, indicate that a large variation occurs among various species and cultivars of cereals, legumes and oilseeds and also in the broad biochemical composition of the three major constituents -carbohydrate, protein and lipid /oil [12, 15, 19, $25,29,37,41,48,53,86]$.

Protein content in different cereals and millets and even in the same crop vary considerably. Say, the protein content of cereals may vary from approximately $7.0 \%$ to $23.0 \%$. In other words, protein content of some cereals and millets is on par with many legumes. In legumes because of crops like lupins and soybean variation becomes wide; lupins having up to 30 to $35 \%$ and soybean having 36 to nearly $40 \%$ protein. Oil seeds also exhibit wide variation in their lipid/oil content with Groundnut and Brassica species having 40 to $49 \%$ oil. A point to be noted here is, they also contain good amount of protein and particularly after the oil is extracted the remaining portion is extremely rich in protein which can be used both for human and livestock consumption. The above variation is attributed both to the genotypes and the environment and management practices [12, 24, 29, 37, 74, 78, 93].

A major concern is that, in general cereal proteins are deficient in lysine, threonine and tryptophan and legumes being deficient in sulfur containing amino acids, methionine and cysteine. In all crops there is a concern for having more PUFA (polyunsaturated fatty acids) [40, 41, 48, 66, 73].

\subsection{Determinate Versus Indeterminate Cultivars}

Most cereal crop cultivars are determinate with specific time periods of vegetative and reproductive phase, while most legumes and oilseeds are indeterminate crops where vegetative growth is maintained simultaneously along with reproductive growth. Harvest index is more variable in indeterminate crops/varieties and they are more likely to be vulnerable to biotic and abiotic stresses. In the same legume species one can have both determinate and indeterminate varieties. Presently, different legumes are grown in different seasons and the incidence of climatic stresses is different in these cases. Farmers are presently coping up with both [30, $32,85]$.

\subsection{Techniques Employed to Understand the Processes and Accomplish the Goals}

To achieve the goals of increasing yield, protein content and desired protein composition knowledge from the crops has been obtained and being obtained and exploited by employing various tools and methodologies Viz; whole genome sequencing, genotyping, association mapping, genome editing, antisense technology, site directed mutagenesis, RNA silencing, bioinformatic tools, GWAS (Genome wide association studies), determining the number of copies of genes for different storage fractions, selective amplification of nutritionally rich genes, expression of heterologous genes, marker assisted selection (MAS), transcriptional and post-transcriptional regulation, translational and post transcriptional regulation and posttranslational modifications, hormonal regulation, regulation by small, micro RNA's, transcription factors, nitrate/ amino acid/amides/ ureide transporters /permeases, transcriptomics, proteomics, metabolomics, phenomics, transgenic technology, CRISPR (Clustered Regularly Interspaced Short Palindromic Repeats)-Cas (CRISPR-associated proteins) technology, high-throughput sequencing, etc [3, 12, 13, 20, $24,43,46,50,61,64,71,82,89,94,98]$.

\subsection{Major Tasks / Success Achieved by Employing Various Techniques}

a) Many seed storage protein genes from cereals, legumes and oilseeds have been isolated, sequenced and their regulation has been studied in transgenic plants. b) The amino acid composition of seed proteins of some transgenic crops has been improved by modifying these genes by site directed mutagenesis or by introducing heterologous genes and overexpressing nutritionally rich heterologous genes c) The synthesis, processing and targeting of the introduced gene products and their stable expression in successive generations of transgenic plants have also been studied d) nitrogen transport and metabolism has been beneficially modified by overexpressing amino acid /ureide transporters. Different categories of transporters with potential applications have been identified. e) with the help of modification of regulatory regions even oil content could be increased in oil seeds f) As a result of so many experiments 
using modern molecular tools a greater insight has been obtained regarding the existing metabolic processes and regulation about nitrogen transport, seed storage protein fractions synthesis, protein quality both in relation to nutrition and food processing, oil content and the yield of the crops $[3,6,10,13,20,46,49,62,69,82,95,97]$.

\subsection{A Summary of All Crops Regarding Xylem and Phloem Composition}

It is well established since long that water and nutrients are transported from roots through xylem to the aerial parts and the aerial parts transports nutrients to roots and developing seeds and other sinks through phloem. Xylem sap composition studies of various crops indicate that nitrogen is predominantly transported in the form of nitrate, amino acids/amides (asparagine, glutamine), ureides (allantoin \& allantoic aicd). In addition to the above forms, some crops may have significant amounts of arginine, homoserine, alanine 4-methylenegutamine/4-methylene glutamic acid. Sulfur in the form of sulfate and other mineral ions are also transported [7, 45, 54, 56, 60, 67, 70, 75].

Phloem sap composition studies of various crops indicate that nitrogen is predominantly transported in the form of asparagine (Asn)/aspartic acid (Asp), glutamine (Gln)/glutamic acid (Glu), and sulfur in the form of methionine, S-methylmethionine, cysteine, glutathione, homo-glutathione and methyl-glutathione. In addition to the above amino acids, citrulline is transported in significant amounts in some crops. Other amino acids are present in varying amounts. GABA (gamma amino butyric acid) also has been detected. Sucrose is the major carbon source transported abundantl. Other sugars transported in varying amounts are raffinose, stachyose, verbascose and the sugar alcohol sorbitol. More interesting for future research is the detection in phloem nucleotide bases, oligo nucleotides of 18-25 bases, (micro) miRNA's, (small interfering) siRNA's, mRNA's and hormones-auxins, gibberellins, cytokinins, abscisic acid. Organic acids particularly malate; minerals particularly potassium; a few proteins and peptides are also transported in phloem. Apparently phloem transported metabolites in addition to being used as a source of nutrients maybe involved in signaling and regulation of metabolism [4, $7,11,23,28,33,36,38,39,43,52,56,70,75,81]$.

\subsection{Nitrogen Utilization}

\subsubsection{Legumes \& Cereals}

Ammonia forming either from Nitrate reduction, BNF (biological nitrogen fixation) or Photorespiration (an important process which is being seriously explored by researches since long for manipulating yield) is initially converted to Glutamine by GS/GOGAT (Glutamine synthetase/ Glutamine-oxoglutarate aminotransferase) pathway. Subsequently glutamine may undergo metabolic inter-conversions. Amino acids (Asp, Glu) / Amides (Asn, Gln) formed in the roots are generally used for the long distance transport of nitrogen among organs through xylem and from leaves to seeds through Phloem. In case of certain legumes predominantly ureides can be formed in roots as a result of BNF. Nitrogen is not only an important constituent of seed storage proteins but also of nucleic acids and several other nitrogen containing compounds which have diverse roles in the plants. In cereals and other crops also the above information is true except for the absence of BNF. In addition to nitrate they may take up some ammonia too. However the important point to be note is nitrate can be reduced either in roots or in leaves or partly in leaves and partly in shoots [9, $34,67,80]$.

\subsubsection{Rationale Behind Amide and Ureide Transport from Roots}

Rationale behind the form of nitrogen transport form roots is not fully certain and/or incomplete. Rationale based on solubility and $\mathrm{N}: \mathrm{C}$ ratios is given since long. The ureides being less soluble than the amides are found only in tropical legumes and they have high $\mathrm{N}$ : $\mathrm{C}$ ratio of $4 \mathrm{~N}: 4 \mathrm{C}$ while amides have a ratio of $2 \mathrm{~N}: 4 \mathrm{C}$ and $2 \mathrm{~N}$ : $5 \mathrm{C}$ in asparagines and glutamine respectively. However, this rationale apparently is not applicable when cereals and other crops grown both in tropical and temperate conditions are compared. In both the cases, it is predominantly amino acids/amides that are transported. Further, arginine and citrulline also have favorable N: C ratios--4N: $6 \mathrm{C}$ and $3 \mathrm{~N}$ : $6 \mathrm{C}$ respectively and their biosynthetic pathway is simpler compared to the biosynthetic pathway of ureides from glutamine which involves purine synthesis followed by purine degradation occurring in roots itself. In fact, many plants do transport significant amounts of arginine and in particular citrulline. Citrulline is the major nitrogenous solute in nodules, roots, stems, leaves, and xylem sap of nodulated and non-nodulated alder and Casuarina. But in general, they are not the predominant forms. A more important point is, even under tropical conditions non-nodulated legumes do not synthesize ureides but predominantly form and transport amino acids/amides. Hence, BNF and the specific nature of symbiotic association has something to do in determining the form of nitrogen that is being transported [16, 54, 60, 80, 82]

\subsubsection{Temperate Versus Tropical Legumes}

Yet another metabolic process which needs to be fully understood even in temperate legumes and some other legumes is the preference to transport amides -asparagine and glutamine. Logic is as follows. Ammonia formed in BNF is initially fixed in Glutamine by Glutamine synthetase. Then glutamine participates in the reaction by GOGAT (glutamineoxoglutarate aminotransferase giving two molecules of glutamic acid. One of them can be recycled for further fixation of ammonia and the other glutamic aicd can be transported as such to the aerial parts. But it does not happen so. Rather, this glutamic acid further fixes one more ammonia to give glutamine and then transported or even then it is not transported but prefers to react with aspartate and form asparagine which is transported. Prokaryotes have ammonia dependent asparagines synthetases. Had legumes and/ or bacteroid evolved/ possessed ammonia dependent 
asparagine synthetase then ammonia formed from BNF can directly interact with aspartate to form asparagines which can be transported. In view of the above, it is a better conclusion to say that the exact reason(s) for the form of transport chosen by the plant is not yet understood and some critical and lateral thinking is required $[13,54,56,67,70,82]$.

\subsubsection{Regulation of Storage Protein Synthesis in Different Crops}

a) Seed development is divided into two main stages: a) Cell division, and $b$ ) seed filling and desiccation/maturation. At the end of cell division phase different storage products are accumulated in endosperm and embryo. Seed storage proteins are regulated temporally and spatially. The synthesis of storage proteins like so many other proteins may be regulated at various levels Viz; number of copies of genes, regulation at transcription, post transcription, translation, post-translation, site of synthesis, transport and deposition. Further, regulation can occur because of nitrogen and sulfur fertilization -both timing and dosage and provision of irrigation. The importance/extent of the above modes of regulation may vary with the crops and cultivars and agroclimatic regions. What is meant by temporal and spatial regulation? From the start of seed development till seed maturity different protein fractions are synthesized at different times. This sequence of expression is specified and is called temporal regulation. During the seed development phase it is also specified where the protein fractions are to be deposited Viz; embryo, endosperm, cotyledons, aleurone layer, embryonic axis etc. This is also specified and is referred to as spatial regulation. Say for example, prolamin genes in rice cultivars are subject to tissue-specific and developmental regulation, being expressed exclusively in the starchy endosperm during mid- and late-development and nutritional regulation responding sensitively to the availability of nitrogen and sulfur in the grain $[6,10,24,35$, $48,61,65,73,89]$.

b) Same amino acids/ amides -Asparagine (Asn) /Aspartic acid (Asp) and/or Glutamine (Gln)/ Glutamic acid (Glu) predominantly transported through phloem to the developing seed but different storage protein fractions are synthesized. Therefore, further metabolism of the transported amino acids are apparently regulated as per the storage protein fraction to be synthesized / mRNA levels. In case the received amino acids from the phloem directly corresponds to the codons of the mRNA then they can be directly incorporated and no further metabolism of them is required. Say for example Glutamine can be directly incorporated particularly in prolamins mRNA's which are rich in glutamine codons. Further, metabolism of the received amino acids from the phloem can be simpler or complex. Say for example glutamic acid can be easily converted to glutamine and vice versa and similarly with Asp and Asn. Glu/Gln is a precursor for proline. Proline can be easily formed from them. But synthesizing lysine or methionine from aspartate is a longer pathway $[61,66]$.

c) The above four mentioned amino acids predominantly transported to the developing seed are non-essential amino acids. Rubisco (Ribulose 1, 5, Bis-phosphate Carboxylase) is the most abundant protein in the leaves degraded during senescence and it has a good essential amino acid composition. Apparently essential amino acids formed during protein degradation in leaves particularly of Rubisco - the most abundant protein and other proteins like light harvesting protein complexes etc -- are not fully transported as such but are catabolized. This catabolization may lead to loss of carbon, nitrogen and decreased levels of essential amino acids thereby decreasing their transport to the developing seed. As in the case of photorespiration though both ammonia and $\mathrm{CO}_{2}$ are released ammonia is totally re-fixed but $\mathrm{CO}_{2}$ is lost. In a similar manner it is possible that during senescence too any ammonia liberated in the biochemical inter-conversions is assimilated and only $\mathrm{CO}_{2}$ is lost. These estimates are not worked out. If $\mathrm{CO}_{2}$ is lost how to prevent or reduce its loss? Maybe a reduction in decarboxylases activity which are responsible for $\mathrm{CO}_{2}$ release but his can be an essential step in some of the metabolic inter-conversions. Alternatively, an increase in the level of carboxylases and the resulting metabolites are transported directly or after further inter-conversion. Till now the concentration /focus was only on amino acids/ureide transporters but not so much on organic acid transporters. Sulfur is supplied by the transport of free methionine \& cysteine, and in the form of tripeptides, glutathione, homo-glutathione, methyl-glutathione and in the form of S-methylmehtionine in varying concentrations $[4,36$, 64, 66, 81].

d) An important point to be realized is, senescence is an energy-dependent process and photosynthesis declines during senescence and the supply of nitrogen from roots also may decline at this stage. Hence, a senescing leaf has limitations to transport carbon and nitrogen to the developing seeds. There is a need to study in greater details biochemical interconversions in the senescing leaves to evolve strategies for increased transport of nitrogen and carbon to the developing seeds $[36,66]$.

i. Nutritional Utility/Substitution of Other Crops

Cereal proteins are deficient primarily in lysine and also in threonine and tryptophan because of high content of prolamins which are deficient in these amino acids. An exception being that of rice and oats which are low in prolamin content. Relatively, rice is better in lysine content though it is still inadequate. However, best oat varieties when grown under best management practices can satisfy the nutritional requirements. Though rapeseed (canola) is valued for its high oil content it also has a high protein content (upto $25 \%$ ) with an excellent composition of essential amino acids compared to other legumes and can be recommended for human consumption. A slight deficiency of lysine is felt. Rapeseed is one of the model organisms where extensive studies have been carried out both by conventional and modern approaches including regulation of storage protein biosynthesis. Similarly, several cultivars of sesame have excellent amino acid composition in their seed proteins and hence can be recommended for human consumption $[3,5,17$, 
$18,21,24,25,27,37,59,78]$.

ii. Gene Amplification of Storage Proteins and over Expression of Transporters

Approach of selective amplification of storage protein genes and expression has been and is being further pursued; say expression of nutritionally rich $2 \mathrm{~S}$ albumins. Amino acid transporters have been studied and have been exploited for improving nitrogen transport. Amino acid transporters may be obtained from different plants and microorganisms.

To improve source-- sink relationships-roots-leavesseeds-, an amino acid transporter from pea plants -- PsAAP1 -was over expressed in pea plants using an Arabidopsis AAP1 promoter that targets gene expression to the phloem as well as to the cotyledon transfer cells. This transporter can recognize and transport amino acids of different categories acidic, basic and neutral apart from citrulline though it seems to have more affinity to lysine. The transgenic pea plants over expressing amino acid permeases showed increased phloem loading and embryo loading of amino acids resulting in improved long-distance transport of nitrogen, sink development and seed protein accumulation $[49,69]$.

\section{Extrapolations, Inferences and Followup on the Basis of What Is Already Known}

\subsection{Nitrogen Reduction, Assimilation and Trasnport}

\subsubsection{Contrast in the Developing and Developed Countries}

An important point to be kept in mind is that the needs and state of affairs of developed countries, food surplus countries and high-income countries is different from that of developing, low income and food shortage countries. Hence, comparing and contrasting them is essential to work out strategies to serve the needy and also the well off. Almost invariably countries in Asia and Africa in particular SubSaharan Africa are mentioned. Of course, an important commonality does exist between these contrasting nations in the food habits; say for example entire sub-saharan Africa are meat eaters. So with other countries in Africa and also in Asia. However, some differ in being non-meat eaters primarily located in India. For that matter even in developed countries there exists vegetarianism and veganism-and vegans are found in these countries too. In fact even traditional meat eaters in different countries are not able to eat meat/the required amount of meat as they cannot afford. That is how and why they are sustaining on vegetable proteins. Further, the influence of modern culture made many traditional vegetarians to start eating meat. Hence, the extrapolations and inferences must be accordingly assessed $[25,27 ’ 29,30,47]$.

\subsubsection{Rhizhobium-Legume Interaction}

The purpose of the Rhizhobium is primarily to fix atmospheric Nitrogen into ammonia. Beyond that, the variability in metabolism is not really understood. Hence, detailed studies be conducted on the relationships between every legume and different inoculating strains and the amino acid/ nitrogen compound that is destined for transport in the xylem and final performance of the crop under the above conditions [58].

\subsubsection{Exploiting Metabolic Variation}

The fact that crops have considerable diversity in nitrogen metabolism Viz; the site(s) of Nitrate reduction and ammonia assimilation; form of nitrogen synthesized and transported and their extent of transport from roots to shoots in the Xylem depending on the external factors; categories of seed storage proteins and their sub-families; variation in protein content and amino acid composition in different crops; reflects their flexibility and potential for manipulation. Hence, regulation of host nitrogen metabolism in nonnitrogen fixing crops, and regulation of host metabolism, bacteroid metabolism and their interactive effects in nitrogen fixing crops needs to be studied in greater depth. Apparently there are factors switching on and switching off of different processes and pathways concerned with the above $[9,78,80]$.

\subsubsection{Amide Versus Ureide Transport}

Some fundamental questions need to be raised, focused and studied. Why some legumes produces ureides while some other produces amides (Asn/Gln)? Is the difference only because of the external temperatures in which legumes are grown? Is it because of the difference in the strains? Is it because of differences in the water availability in these category of legumes? These questions can be investigated in controlled experiments in environmental chambers and even in pot and field conditions accordingly designed. Is it possible to prevent ureide biosynthesis in tropical legumes and make them as amino acid/ amide producing? Or Vice Versa ? Even turning ureide producing legumes into arginine or citrulline transporting is theoretically less expensive energetically/biosynthetically simpler than uredies, wherein fixed ammonia/ glutamine has to be initially diverted to the process of purine synthesis followed by purine degradation to give the ureides, allantoin and allantoic acid. Further, they have to be metabolized in leaves and once again ammonia needs to be re-fixed. $\mathrm{CO}_{2}$ liberated in this process is not known whether it can be entirely conserved or is lost partly or wholly. In photorespiration both $\mathrm{CO}_{2}$ and ammonia are released in leaves but only ammonia is re-fixed but $\mathrm{CO}_{2}$ is lost [16, 34, 54, 56, 67, 69, 82].

\subsubsection{Site of Nitrate Reduction and Effect of Exogenous Nitrogen on BNF}

Is it possible to accomplish nitrate reduction entirely in leaves in those crops where it is presently reduced either partly or wholly in the roots? Because, reduction of nitrate in roots demands the import of carbon from leaves. Soybean can utilize nitrate and ammonia even under nodulated conditions but in these cases, the transport form of nitrogen are asparagine and glutamine. In other legumes addition of external nitrogen has only been shown to inhibit biological nitrogen fixation (BNF) but no additional benefit. Why BNF is not affected in soybean because of addition of nitrogen 
fertilizer? Answer given is, it has genetically a high protein content which requires high nitrogen and so it accepts additional nitrogen and probably the root architecture vis-àvis nodules also favors the acceptance of exogenous nitrogen fertilizer. But this does not satisfactorily answer the question of external nitrogen inhibiting BNF in other legumes $[9,34$, $54,80]$.

\subsubsection{Root Ideotype}

When nodules also decline in their ability in later stages external fertilization maybe attempted during seed filling period to see if there is any increase protein content /quality. One may start with small amount of nitrate addition and make them adaptable over successive generations to higher external dose of nitrate. An alternative thinking is, soybean root ideotype is different from other legumes. Hence, a comparative study of root ideotypes of soybean and other legumes-tropical and temperate both under nodulated and non-nodulated conditions-- must be made. Search for genes determining/influencing the root ideotypes need to be identified. In crops other than legumes, there is no difference in the form of nitrogen transported from roots, irrespective of whether they are grown under tropical or temperate conditions or irrespective of whether they are grown in water limiting conditions or non-water limiting conditions. In all cases they transport nitrogen in the same form. Hence, it is something which is unique to legumes and something which has to do with the BNF process interaction with the legumes $[30,32,60,70,85]$.

\subsubsection{Growing Legumes in Non-native Environments}

Soybean is also an exception in that even at pod stage ureides are transported through xylem to pods whereas they receive nitrogen in the form of amides and amino acids from leaves through phloem. It is worth growing tropical legumes under temperate conditions and vice versa to know the form of nitrogen transport. Even if their performance is less a definite information about the form of transport of nitrogen from roots will be obtained which is worthwhile.

\subsubsection{Role of BNF in Nitrogen Transport and Nitrogen Transport in Other Crops and Conditions}

Rationale behind the form of nitrogen transport from roots is not fully certain and/or incomplete. Rationale based on solubility and $\mathrm{N}: \mathrm{C}$ ratios is given since long. The ureides being less soluble than the amides are found only in tropical legumes and they have $\mathrm{N}$ : $\mathrm{C}$ ration of $4 \mathrm{~N}: 4 \mathrm{C}$ while amides have a ration of $2 \mathrm{~N}: 4 \mathrm{C}$ and $2 \mathrm{~N}: 5 \mathrm{C}$ in asparagines and glutamine respectivley. However, this rationale is apparently not applicable when cereals and other crops grown both in tropical and temperate conditions are compared. In both the cases it is predominantly amino acids/amides that are transported. Further, arginine and citrulline also have favorable N: C ratios-4N: $6 \mathrm{C}$ and $3 \mathrm{~N}$ : $6 \mathrm{C}$ respectively and their biosynthetic pathway is simpler compared to the biosynthetic pathway of ureides from glutamine which involves purine synthesis followed by purine degradation occurring in roots itself. In fact many plants do transport significant amounts of arginine and in particular citrulline. A more important point is even under tropical conditions under non-nodulated conditions legumes do not synthesize ureides but predominantly form and transport amino acids/amides. Hence, BNF and the specific nature of symbiotic association has something to do in determining the form of nitrogen that is being transported. Apparently, the infected Rhizhobium is inducing the ureide biosynthetic enzymes which are otherwise suppressed under non-nodulated conditions. Soybean is an exception in that even under nodulated conditions it does transport significant amide asparagine and under non-nodulated conditions also it can synthesis of some amount of ureides. From this it is clear that ureide biosynthetic genes are present in, many legumes but their expression is regulated differentially and is linked in yet unknown ways to the BNF process. It is a better conclusion to say that the exact reason(s) for the form of transport chosen by the plant is not yet understood [21, 24, 25, 27, 39, $42,54,59,75,80,86,93]$.

\subsubsection{Advantages of Different Forms of Nitrogen Transport}

Though ureides have been projected as advantageous because of their high nitrogen to carbon ratio, their biosynthesis is circuitous and they need to be re-metabolized once again in the sinks to produce amino acids for incorporation into proteins. It should be noted that arginine is a protein amino acid which can be directly incorporated into proteins and arginine too has high nitrogen identical to ureides i.e $4 \mathrm{~N}$ though the ration of nitrogen carbon is $4 \mathrm{~N}$ : 6C. In many plants seed proteins can have $40-50 \%$ of total nitrogen as arginine. Further, it can be metabolized to other amino acids like proline, glutamic acid besides its other potential beneficial roles for the plant. In roots its biosynthesis either from exogenous nitrate reduction or ammonia uptake or from nitrogen fixation by BNF is a simpler process than ureides and as mentioned above it has high nitrogen identical to ureides. Hence, arginine as a transport form of nitrogen both in phloem and xylem i.e from roots seems to be a worthwhile strategy pursuing. In any case such pursuit will contribute a lot to our understanding of the nitrogen metabolism and source - sink relations $[14,16,45$, $53,54,67,70]$.

\subsubsection{Nitrogen Contribution of Roots Versus Shoot}

Normally, whatever maybe the form of nitrogen transport, roots transport them through Xylem to leaves delivered via phloem loading. It is the leaves which in turn nourishes the developing seeds. In soybean however a significant amount of ureides are directly transported through xylem to podspodwall to be apt. The usual reason attributed for developing seeds and pods not receiving nitrogen directly from xylem is attributed to lack of pressure in these organs and lack of transpirational pull. The fact that in soybean xylem transport of nitrogen is there even at pod stage indicates that BNF is active and roots are more active even at later stages compared to other legumes and crops. In other crops probably roots senesce by this time and become weak to transport nitrogen. In case root system is more 
active in cereals, oil seeds and other crops during seed development phase is a beneficial situation to these crops. Hence, root senescence need to be studied and efforts be made to increase the activity of root system during seed filling phase. More data is required on the amount of nitrogen taken up from the soil during the reproductive phase and delivered to the leaves. This will indicate the relative proportions of direct contributions of soil nitrogen versus nitrogen mobilized into the seed as a result of already stored protein degradation in senescing leaves. This depends primarily on how active roots are even at the stage of seed development $[7,9,16,23,33,36,40,43,47,54,56$, $60,67,69,75,76,81,82,83,87,97]$.

\subsection{Importance, Regulation and Manipulation of Nitrogen Transport and Seed Storage Proteins}

\subsubsection{Metabolic Re-working of Amino Acids}

Amino acids transported through phloem have no bearing on the amino acid composition of seed storage proteins going to be expressed. Hence, it is only metabolic reworking of the same amino acid/amides that is accomplishing the synthesis of different storage protein fractions. Can a change in amino acid composition of phloem sap reaching the developing seeds (i.e amino acid reworking in senescing leaves and ensuring their subsequent transport) regulate differentially gene expression of seed storage proteins? $[9,66]$

\subsubsection{Importance of Storage Proteins for Seed Germination Versus Human Nutrition}

There is yet another way in which nitrogen transport has to be viewed and understood. Amount of storage protein fractions-Albumins, Globulins, Glutelins, Prolamins-- and amino acid composition of these fractions are different among different crops. In spite of that all seeds successfully germinate. In other words seeds have the capacity for metabolic reworking and derive all the protein amino acids required during seed germination and seedling growth. Similarly, nitrate /ammonia is initially fixed into glutamine and asparagines or ureides and transported through xylem to the leaves. From these transported forms of nitrogen leaves have the capacity to derive all the protein amino acids required. The point to be understood here is amino acids require not just amino group/nitrogen but also a require a different carbon skeleton for each of the protein amino acid. This carbon skeleton is provided by the intermediates of glycolysis, TCA cycle, HMP pathway and Calvin cycle. In photosynthesis energy and reductant required for the amino acid biosynthesis is also produced. But in non-photosynthetic organs energy and reductant are produced by gycolysis and TCA cycle and HMP pathway. The amino group required usually provided by Aspartate, Asparagine, Glutamine and Glutamic acid which are also the predominant forms of nitrogen transport both in xylem and phloem and the enzymes involved in these reactions/interconversions are GS/GOGAT, Aspariginase, Asparagine amiodo transferase, and aspartate amino transferase (GOT) and alanine amino transferase (GPT) $[9,36$, $41,42,44,45,48,49,62,66,78]$.
The above biochemical details provides a justification for the predominant transport of the above mentioned amino acids to developing seeds via phloem. In the seeds -which are not photosynthetically active - the abundant sucrose supplied from leaves is metabolized in the seeds to generate the required carbon intermediates for all the required amino acids and the transported amino acids serve to donate amino groups. In such a case the a more promising way to increase protein content is to further increase the flow of the above transported amino acids and sucrose.

\subsubsection{Cell Division versus Cell Expansion}

As mentioned above the first phase is the cell division phase. Does developing seed during mitosis depends exclusively on phloem derived hormones or does it synthesize to some or greater extent ? Even if number of cells are increased to fill them i.e full cell expansion requires a large amount of nutrient diversion to seeds which in turn may require additional fertilization and/or enhancement in photosynthesis and remobilization from sources. Enhanced photosynthesis may not be possible as leaves are getting senesced gradually during which time Rubisco is being degraded. Further, roots also are getting inactive.

An empirical approach of spraying growth regulators on plants or using in tissue culture was followed for a long time and is still followed. As hormones except ethylene have been implicated in embryonic and endosperm cell division and enlargement and maturity, why not an empirical approach of spraying different permutations and combinations of hormones during seed development phase on different parts of the plant? $[5,19,40,43,76,96]$

\subsubsection{Genes for Determinative Type}

Like genes for dwarf vanities there could be genes for determinate varieties which can be introduced into indeterminate varieties. This maybe useful. In soybean and faba bean both determinate and indeterminate cultivars are available. So the genes are from the same source and so genetic engineering maybe more easily successful. And these genes may also be introduced into other legumes. Depending on the outcome -on comparing determinate and indeterminate varieties -- farmers may accordingly decide to use the varieties $[15,30,32,54,60,85]$.

\subsubsection{Nucleic Acid Catabolism During Senescence}

More studies are required on Nucleic acid catabolism in senescing leaves involved in nutrient transport. It is not known how much of the catabolic products are exported and how much is recycled in the leaf itself for the senescence process to operate. As phloem sap composition contains NTP's and small/micro RNA's it appears that degraded RNA's are transported as above and the latter can be involved in RNA signaling. NTP's can also arise from the degradation of DNA in nucleus, mitochondria and chloroplasts of senescing leaves and other sources transporting nutrients like stems etc. Search and study of nucleotide transporters is useful $[7,33,36,43,56,70,75]$. 


\subsubsection{Role of Methionine and Methyl Groups}

Three metabolites can donate methy group-Viz; SAM (Sadenosylmethionine; tetrahydrofolate $(\mathrm{H} 4)$ and $\mathrm{S}$ Methylmehtionine (SMM). SAM is a more effective donor. SMM is one of the metabolites transported in crops. SMM can be converted to Methionine. The question that arises is why SMM is transported instead of methionine ? Apparently, SMM acts as methyl group donor to different compounds. For DNA methylation -whereby genes are regulated-- it is SAM which acts as a methyl group donor. It is speculative whether the additional methyl group in SMM plays any role in DNA methylation and gene regulation $[4,81]$.

\subsubsection{Importance of Traditional Approaches}

Wherever and in whichever crops traditional approaches and strategies are still possible like bridging the yield gap, increasing the harvest index etc may be pursued. Though researches are trying to increase yield and protein constant and quality by modern molecular tools, it should be realized that there are large germplasm collections in many crops and so conventional breeding approaches are possible to achieve the goals. And these germplasm collections also serve as a source of useful genes which can be exploited using modern molecular tools [30, 32, 85].

\subsubsection{Manipulaitng Temporal and Spatial Regulation of Seed Storage Proteins}

Seed storage protein genes are temporally and spatially regulated. Hence, correct understanding of the timing and sequence of expression of different storage protein fractions during the seed development period -from initiation to final maturity in different seed tissues (embryo, endosperm etc) is required. Regulatory regions in the upstream of 5 prime region must be earmarked correctly which can be successfully fused to the coding region of nutritionally better protein genes from the same or heterologous source. Further, a greater understanding of 5 prime and 3 prime UTR's (untranslated regions) of mRNA's of different storage protein fractions is required to control mRNA stability.

Pea Legumin gene expression was also shown to be temporally regulated during seed development. Legumin polypeptides and mRNA began to accumulate 16 days after flowering (DAF), in contrast to the endogenous tobacco storage proteins which were apparent at 13 DAF. So expression of legumin is similar in both pea and tobacco. Apparently such regulatory regions can be found which can be used to express genes in heterologous hosts. Such experiments should be carried out also in edible crops in addition to model plants for studying gene expression $[6,10$, $12,25,48,61]$.

\subsubsection{Chimeric Genes}

Cloning of chimeric genes for seed storage protein fractions may be attempted. Part of the coding region of native gene which is usually expressed may be fused with part of a nutritionally desirable coding region of another gene, keeping the overall length of the gene similar to the complete native gene. In cases where only the nutritional deficiency of specific amino acid(s) is to be alleviated even a small portion of foreign gene maybe sufficient in the chimeric gene and in such cases the possibility of mRNA's being successfully translated can be speculated to be high.

In the task of increasing oil content the strategy of chimeric promoters has been exploited. Here the chimeric promoters have been created using seed specific promoters of storage protein genes with promoters of genes involved in fatty acid and triglyceride biosynthesis. When such chimeric promoter was introduced into Arabidopsis oil content increased by $18-73 \%$ compared with wild-type seeds. The novel expression profile of the hence using of this chimeric promoters strategy may be extended to legumes and exploited for manipulating the seed storage protein content and/ or amino acid composition [3, 25, 61].

\subsubsection{Selection of Suitable Transporters}

Alteration of amino acid and ureide import into the collection phloem has been projected as a highly promising strategy potential for plant improvement, A dramatic improvement in the nitrogen metabolism occurred when a common bean UPS1 transporter (ureide transporter) was expressed in cortex and endodermis cells of soybean nodules. Symbiotic nitrogen fixation, number of transgenic nodules, transport of nitrogen from nodules to shoot and seed set were all significantly increased. This experiment clearly indicates the importance of transporter activity. However, over expression of transporters may divert more nitrogen towards transporter synthesis as they also are proteins. Hence, a better strategy is to search for transporters which have high half life and high affinity for the concerned amino acid(s) / ureides $[25,45,49,69,82,94]$.

\subsection{Need for More Information on Agronomic, Breeding and Physiological Parameters}

\subsubsection{Manipulating Cultural and Environmental Parameters}

How about giving more water and see whether ureide transporting tropical legumes can be made amide transporters or made to increase amide transport ? Alternatively it would be interesting to conduct trials in controlled environmental chambers/ glass houses where temperature may be altered and see whether nitrogen transport can be altered in tropical and temperate legumes. Will they change their modes of transport of nitrogen compounds because of changing temperature and water availability? In fact tropical legumes are transporting predominantly amides under non-nodulated conditions. So a change in a variable can change the form of transport. So quite likely temperature also may bring that change and this can be studied only under controlled environmental conditions or growing the native legumes in another environment - tropical legumes grown in temperate conditions and vice versa. Here the curiosity is to know the form of transport and not a concern for yield etc. This is only to understand the links between $\mathrm{N}$ assimilation and form of transport. Subsequently, further planning can be thought of. Hence, this is worth studying $[30,32,37,38,47,57,72,85$, 
99].

\subsubsection{Combine Both Agriculture and Animal Husbandry}

Children or adults suffering from malnutrition is not always because of rice/ cereals being staple food but unfortunately their poverty /low income levels does not allow them to grow and consume meat from any source to overcome protein malnutrition. Hence, agriculture and animal husbandry - both terrestrial and aquatic-- must be duly focused depending on their food habits and resources in the above regions $[18,30]$.

\subsubsection{Starch Versus Oil Versus Protein}

Oil seeds which have both considerable starch, oil and also protein offers an unique opportunity for manipulating the nutrient composition. Both oil and starch do not contain nitrogen while protein requires nitrogen. The carbon that is received by the seeds theoretically can be diverted either to starch or oil to varying extent. Manipulating their relative proportions is theoretically a lesser metabolic task than manipulating protein content as it has a nitrogen demand in addition to carbon demand. If protein content is increased, as amino acids have carbon skeleton proportionately carbon has to be diverted to proteins and this can be at the expense of starch and/or oil depending on the crop. But for human nutrition this may not pose a problem as there is abundant starch in both cereals and legumes and enough oil in oils seeds which have high calorific value $[3,25,27,29,59,62$, 86].

\subsubsection{Need for More Information on Phloem Composition}

Phloem composition should be analyzed throughout the grain filling period starting from first day of grain filling till maturity. Currently data is available only for certain days during grain development. This information is to be analyzed for all categories of crops - cereals, legumes and oil seeds Similarly more samples need to be analyzed for Xylem sap composition throughout the crop growth $[7,70,75]$.

\subsubsection{Crop Seasons and Durations}

Crop duration and the different phases of crop growth must fit into the local seasons and the farmers must be able to sow the next crop in time. Hence, increasing the duration of the crop is not always an attractive/feasible strategy for increasing yield or quality. Any improvements must be within the same duration of crop growth or any increase in duration should be within the limits i.e without affecting the sowing of the next crop $[30,32,85]$.

\subsubsection{More Information on Harvest Index}

Harvest Index data is usually given with respect to human edible dry matter. In addition more details are required Viz; harvest Index for nitrogen, carbon and sulfur taking into consideration both aerial and underground biomass. While Harvest index data is recorded attention should be given to the indeterminate type/nature of crops and any abscission of plant parts-leaves, flowers, pods etc. In case both types are found in the same crop data should be given both for determinate and indeterminate and duly compared. Biochemical changes and metabolic interconversion must also be studied in stems and roots in addition to leaves. For studies on underground biomass and biochemical changes in roots some special designing is required. In economic yield, value of non-consumable parts by human like leaves, stem, husk, pod wall seed coat etc must also be evaluated along with their chemical composition. They may be used for livestock consumption if not for human consumption. As in addition to seed, other parts Viz; underground tubers, aerial stems, leafy vegetables etc can be consumed by humans the above information may be generated accordingly [30, 32, 85].

\subsubsection{Temperature Resistant Varieties}

Crop harvest indices can be reduced by pests and diseases through impacts on flowers or seed and pod development, or indirectly through destruction of grain. Similarly, changes in temperature affects grain development and filling. From a survey of meteorological data, an average temperature during grain filling can be determined -and also during the life cycle - and accordingly temperature resistant varieties maybe developed [27, 30, 62, 72, 85].

\subsubsection{Plants May Have Compensatory Mechanisms}

An important point to be noted is many researchers are of the opinion that Harvest indices have reached a plateau for many crops within the range 0.5 to 0.65 . So scope for improvement of harvest index exists only in some crops and cultivars and in some regions. Researchers involved in crop improvement should be aware of the fact that crops may have compensatory mechanisms. Say for example an increase in number of tillers may reduce the number of productive tillers, increase in panicle number may decrease the number of spikelets and /or the number of spikelets filled or the extent to which spikelets are filled; increase in protein content may decrease the yield, if number of pods are increased, seeds per pod may decrease or if number of seeds per pod are increased seed weight can decrease etc. Plant produces seeds for its propagation. After manipulating the nutrient composition it is essential to also study their germinability, vigour of seedling growth, viability/storability of seed under ambient conditions. No much data is given by the researchers though they have studied their transgenic plants and non-transgenic in succeeding generation. Above data needs to be generated. Drastic modifications may have unintended consequences.

\subsubsection{Farmers Wish}

Of course the ideal thing and what the farmer wants is to have the required yield/ increase yield and protein content or any other seed reserve without the need of any additional external fertilizer and other inputs. If cost of inputs is increased, the farmers income decreases, apart from environmental consequences. For this all the above mentioned processes and strategies have to be explored further. Two major approaches which are being actively pursued Viz; abolishing/reduction in photorespiration al and conversion of C3 crops into C4 crops have not been discussed here [63, 64, 
68].

\section{Conclusion}

So experiments need to be planned keeping in view of the above questions and information. Whether this is beneficial or not and if so how can be known only after the experiments are successful. Presently, it can be argued in more than one. In any case experiments in the above direction will yield valuable information for further developments.

\section{Suggestions and Creating Awareness to the Public}

\subsection{Assessing Priorities}

The primary interests and concerns for advanced countries are different than that of deprived countries and regions. Relevance and objectives of increasing yield and protein content and quality in developed countries -where food surpluses are already there-are apparently different than the same goals being pursued in developing countries. In developed countries grains are fed for animal consumption for the sake of more and better meat, for processed foods, and the grains have industrial applications. In developing and poor countries the primary need is of good and adequate food for humans. Of course science for science sake is always pursued by the economically well off with some hope of long term benefits in some as yet unknown ways. Further their research may also turn out to be of human concern -presently deprived ones. Green revolution was so but it was accomplished by conventional approaches. But now advanced molecular tools are being used to accomplish the goals of crop improvement.

\subsection{Consumption of Alternative Food Items}

There is a time dimension for the goals to be achieved either by conventional or by using modern technology or combining both. Till then some measures need to be suggested for people to tide over their crisis. Rubisco protein is accumulated in large amount sin leaves and it has a balanced essential amino acid composition. Hence people should cultivate the habit of eating different leafy vegetables in considerable quantities to supplement their staples. In fact many are consumed but in low quantities, like spinach, alfalafa, fenugreek etc. People should increase their consumption. Presently, they are consumed to a lesser extent. Growing them also is not a problem. In addition to leaves even seeds of many crops like amaranth, mustard, sesame, tomato, grape seed, apricot etc can be nutritionally beneficial with or without further processing. The emphasis should be on health rather than on the taste of the palate. Those which are not fit for human consumption maybe used for livestock. After extracting the oil, oil seeds also are a rich source of protein which is fed to animals and consumed less by humans. As far as possible it is suggested that this protein is consumed by humans and is accordingly processed. Depending on the food habits it may be judiciously decided how much of this protein can be fed to animals and how much should be spared for human consumption. Similarly skins of many fruits, both on the outer coat inner portion of the fruits provide valuable fibre and other nutrients and in fact consumed by many if not all. The habit of consuming skins without throwing away must be cultivated by the deprived. Deprived should be created due nutritional awareness and health care precautions.

\subsection{Alternative Enterprises and Knowledge of Suitable Dietary Patterns}

One of the reason for meat being expensive is because of its feed. As in olden times if animals are fed with fodder from the crops which is unfit for human consumption then the meat is likely to be less expensive. Similarly, if enterprises like aquaculture, poultry are taken on a small scale they can alleviate the problem of the poor for their nutritional requirements. Further, if natural fishing is possible from rivers and lakes, and seas they may resort to it. Another alternative is to resort to different crops and take a mixture of items as food including meat produced by lesser investment. Processed foods need to be avoided as they are more expensive. Similarly, the urge for imported food items need to be controlled. A diet pattern which can be afforded keeping in view their income status-- must be designed by the nutritionists and dieteticians. Of course in all these recourses one may have to sacrifice the taste for palate to survive within the means of income. As invariably mentioned by all these nutritional problems and the problem of alleviation is confined to certain countries and continents. So they have to bear with till the situation is improved.

Land diversion towards non-food purposes must be stopped and strategies to increase farmers income be worked out. Public may be advised to change their food habits to suit to local crop patterns and animal husbandry. Public must be duly appraised about the RDA (recommended dietary allowance) for nutrient consumption. Similarly, crop pattern and land requirement-both type and area-- for meeting the food demands for vegetarians and different meat eaters may be recommended Further water resources and water bodies in the regions also should be kept in mind.

\subsection{International Aid}

Till the deprived people standards are raised International aid in all respects must be provided and their societies well administered. This is a vital measure for ensuring food security for the deprived.

\section{Acknowledgements}

My sincere thanks to the graduate students, Mr. Anil Kumar and Mr. Prabhas for sparing the laptop. Mr Anil Kumar is specially thanked for helping me in formatting the references corrections in the type set manuscript. I am highly thankful to Mr. Raja who has been delivering essentials to my home during this lockdown period. Further, 
I express my gratitude to Dr. S. Sivaramakrishnan, Head, Department of Biotechnology and Dr. S. Sridhar, Honorary Professor, Department of Biotechnology, Bharathidasan University for day to day help during this Corona crisis period. My sincere thanks are also due to Dr. Ramkumar Yadav, Professor (Retired), Department of Plant Breeding, CCS Haryana agricultural University, Hisar for useful discussions.

\section{Conflict of Interest}

Author declares that he has no conflict of interest.

\section{References}

[1] Aard de JongMaaike Nieuwland $14^{\text {th }}$ December (2010). Literature study on the properties of Rubisco-TNO report V9436; 34 pages.

[2] Aluko, R. E. (2017). Hemp Seed (Cannabis sativa L.) Proteins. Sustainable Protein Sources, 121-132. doi: 10.1016/b978-0-12-802778-3.00007-x

[3] Aoyagi, T., Kobayashi, M., \& Kozaki, A. (2018). Design of a Seed-Specific Chimeric Promoter with a Modified Expression Profile to Improve Seed Oil Content. International Journal of Molecular Sciences, 19: 1667-1678.

[4] Bourgis, F. et al (1999). S-Methylmethionine Plays a Major Role in Phloem Sulfur Transport and Is Synthesized by a Novel Type of Methyltransferase. The Plant Cell Online, 11: $1485-1498$

[5] Bojórquez-Velázquez, E., Barrera-Pacheco, A., EspitiaRangel, E., Herrera-Estrella, A., \& Barba de la Rosa, A. P. (2019). Protein analysis reveals differential accumulation of late embryogenesis abundant and storage proteins in seeds of wild and cultivated amaranth species. BMC Plant Biology, 19 (1) article number 59.

[6] Boyer, S \& Shotwell, Mark and Larkins, Brian. (1992). Evidence for the translational control of storage protein gene expression in oat seeds. J. Biol. Chem. 267: 17449-17457.

[7] Balint, T., and Rengel, Z. (2011). Amino acid composition of xylem and phloem sap varies in canola genotypes differing in nitrogen- and sulfur-use efficiency. Crop and Pasture Science, 62: 198.-207.

[8] Bourgis, F et al; (1999). S-methylmethionine plays a major role in phloem transport is synthesized by a novel type of methyl transferase. The Plant Cell, 11: 1485-1498.

[9] Buchnan, B., W. Gruissem and R. L. Jones (2000). Biochemistry and Molecular Biology of plants. American Society of Plant Biology Publications.

[10] Chandler, P. M., Higgins, T. J. V., Randall, P. J. and Spencer, D. (1983). Regulation of legumin synthesis and levels of mRNA. Pl. Physiol. 71: 47-54.

[11] Chen, S. (2001). Long-Distance Phloem Transport of Glucosinolates in Arabidopsis. Pl. Physiol., 127: 194-201.

[12] Chen, P et al (2018) Total 16 authors - Genetic basis of variation in rice seed storage protein (albumin, globiulin, prolamin and glutelin) content revealed by genome wide association analysis. Frontiers. P1. Sci. 9: 612-629.

[13] Collier, R. and Tegeder, M. (2012). Soybean ureide transporters play a critical role in nodule development, function and nitrogen export. The Plant Journal. $\mathrm{http}: / /$ onlinelibrary.wiley.com/doi/10.1111/j.1365313X.2012.05086.x/full

[14] Craig, C. L. and Weber, R. S. (1998) -Selection costs of amino acids in Col E 1 and ColI A gene clusters harbored by Escherechia coli. Molecular Biology and Evolution- 15: 774776.

[15] Casey, R. and Short, M. N. (1981). Variation in amino acid composition of legumin from Pisum. Phytochemistry, 20: 2123.

[16] Carter, A. M. and Tegeder, M. (2016). Increasing Nitrogen Fixation and Seed Development in Soybean Requires Complex Adjustments of Nodule Nitrogen Metabolism and Partitioning Processes. Current Biology, 26: 2044-2051.

[17] Di Stefano, E., Agyei, D., Njoku, E. N., \& Udenigwe, C. C. (2018). Plant RuBisCo: An Underutilized Protein for Food Applications. Journal of the American Oil Chemists' Society, 95: $1063-1074$

[18] Davis, T. A., Nguyen, H. V., Bravo, R. G., Fiorotto, M. L., Evelyn, M. J., Lewis, S. D., D. Rick Lee, D., and Reeds, P. J. (1994) Amino acid composition of human milk is not unique. J. Nutr. 124: 1126-1132.

[19] Dhawan, K. Malhotra, S. Dahiya, B. S. and Singh, D. (1991) Seed protein fractions and amino acid composition in gram (cicer arietinum) Plant Foods for Human Nutrition 41: 225232 .

[20] Domoney, C., Barker, D., \& Casey, R. (1986). The complete deduced amino acid sequences of legumin?-polypeptides from different genetic loci in Pisum. Plant Molecular Biology, 7: 467-474.

[21] David, M Peterson, oats (second Edition) 2011. https://www.sciencedirect.com/topics/agricultural-andbiological-sciences/oat-protein

[22] Hopkins, W.G., 1999. Introduction to plant physiology (No. Ed. 2). John Wiley and Sons.Encyclopedia of Grain Science (2004) - Elsevier, 472-480.

[23] Fukumorita, T and Chino, M. (1982) Amino acid and inorganic contents in rice phloem sap. Plant Cell Physiol. 23: 273-283.

[24] Fauteux, F. and Strömvik, M. V. (2009). Seed storage protein gene promoters contain conserved DNA motifs in Brassicaceae, Fabaceae and Poaceae. BMC Plant Biology, 9: 126.-136.

[25] Gacek, K., Bartkowiak-Broda, I., and Batley, J. (2018). Genetic and Molecular Regulation of Seed Storage Proteins (SSPs) to Improve Protein Nutritional Value of Oilseed Rape (Brassica napus L.) Seeds. Frontiers in Plant Science, 9. July 890-898. Article 890.

[26] Gatehouse, J. A., Croy, R. R. D., Boulter, D. and Shewry, P. R. (1984). The synthesis and structure of pea storage proteins. Critical Reviews in Plant Sciences, 1: 287-314.

[27] González-Pérez, S. and Arellano, J. B. (2009). Vegetable protein isolates. Handbook of Hydrocolloids, 383-419. doi: $10.1533 / 9781845695873.383$ 
[28] Griffiths, C. A., Paul, M. J. and Foyer, C. H. (2016). Metabolite transport and associated sugar signalling systems underpinning source/sink interactions. Biochimica et Biophysica Acta (BBA) - Bioenergetics, 1857: 1715-1725.

[29] Guerrieri, N. and Cavaletto, M. (2018). Cereals proteins. Proteins in Food Processing, 223-244. doi: 10.1016/b978-008-100722-8.00009-7

[30] Gurdev S K. (2005) Green revolution: Challenges ahead. In Proceedings of the internaitonal congress "In the wake of the double helix: From the green revolution to the gene revolution" 27-31 May 2003, Bologna, Italy 37-51; Avenue Media, Bologna, Italy.

[31] Hagop, E. G., Younis, S. A. and Shahatha, H. A. Proteins and amino acids of some local varieties of rice seeds (Oryza Sativa L.) (1990). Plant Food Hum Nutr 40: 309-315. https://doi.org/10.1007/BF02193855

[32] Hay, R. K. M. (1995). Harvest index: a review of its use in plant breeding and crop physiology. Annals of Applied Biology, 126: 197-216.

[33] Hayashi, H. and Chino, M. (1990) Chemical composition of Phloem sap from the upper most internode of the rice plant. Plant Cell Physiol. 31: 247-251.

[34] Heldt, H-W., and Piechulla, B. (2011) Plant Biochemistry (Fourth Edition) Academic Press, 2011, Pages 349-357.

[35] Higgins, T. J. V. (1984) Synthesis and regulation of major proteins in seeds. Ann. Rev. Pl. Physiol. 35: 191-221.

[36] Hostensteiner, S., Feller, U (2002). Nitrogen metabolism and remobilization during senescence. J. Exp. Bot. 53: 927-937.

[37] Huyen, T. T. T., Mui, N. V. and Bang, C. P. (2016) amino acid composition and nutritional value of seed proteins in Sesame (Sesamum Indicum L.) cultivars grown in Vietnam. International Journal of Agricultural Technology, Vol. 12 (5): 939-946

[38] Joost T et al (2004). Phloem Import and Storage Metabolism Are Highly Coordinated by the Low Oxygen Concentrations within Developing Wheat Seeds DOI: https://doi.org/10.1104/pp.104.040980

[39] Joshi, V. and Fernie, A. R. (2017). Citrulline metabolism in plants. Amino Acids, 49: 1543-1559.

[40] Kapoor, A. C. and Heiner, R. E. (1982). Biochemical changes in developing wheat grains. Changes in nitrogen fractions, amino acids and nutritional quality. Journal of the Science of Food and Agriculture, 33: 35-40.

[41] Kawakatsu, T. and Takaiwa, F. (2019). Rice proteins and essential amino acids. Rice, 109-130. doi: 10.1016/b978-012-811508-4.00004-6

[42] King, J. E. and Gifford, D. J. (1997). Amino Acid Utilization in Seeds of Loblolly Pine during Germination and Early Seedling Growth (I. Arginine and Arginase Activity). Plant Physiology, 113: 1125-1135.

[43] Lachlan J. P. and James C. R. Stangoulis. Changes in the Elemental and Metabolite Profile of Wheat Phloem Sap during Grain Filling Indicate a Dynamic between Plant Maturity and Time of Day (2018). Metabolites MDPI Metabolites 8: 53-64. doi: 10.3390/metabo8030053

[44] Lancien, M, Lea, P. J. and Azevado, R. A. (2007). Amino acid synthesis in plastids. In the structure and function of plastids
(Eds. Wise, R. R. and Hoober, J. K) Springer, 355-385. doi10.1007/978-1-4020-4061-0_18

[45] Lohaus, G., Buker, M., Hussman, M., Soave, C. and Heldt, HW. (1998). Transport of amino acids with special emphasis on the transport of Asparagine in the Illinois high protein strains of maize. Planta, 205: 181-188.

[46] Mahender, A., Anandan, A., Pradhan, S. K. and Pandit, E. (2016). Rice grain nutritional traits and their enhancement using relevant genes and QTLs through advanced approaches. Springer Plus, 5 (1). doi: 10.1186/s40064-016-3744-6

[47] Mae, T. (2011). Nitrogen acquisition and its relation to growth and yield in recent high-yielding cultivars of rice (Oryza sativa L.) in Japan. Soil Science and Plant Nutrition, 57: 625-635.

[48] Mandal, S. and R. K. Mandal (2000) Seed storage proteins and approaches for improvement of their nutritional quality by genetic engineering. Curr. Sci. 79: 576-589.

[49] Miranda M, Borisjuk L, Tewes A, Dietrich D, Rentsch D, Weber H and Wobus U. (2003). Peptide and amino acid transporters are differentially regulated during seed development and germination in faba bean. Plant Physiol. 132: $1950-1960$.

[50] Mickowska, B., Socha, P., Urminaska, D., Cieslik, E. 2012. The comparison of prolamins extracted from different varieties of wheat, barley, rye, and triticale species: Amino acid compostion, electrophoresis, and immunodetection. J. Micriobiology., biotechnology and food sciences, 1: 742-752.

[51] Mohr, H. P. and Schopfer (1994). Plant Physiology. Fourth Edition. Springer Verlag.

[52] Munier-Jolain, N. (2003). Can sucrose content in the phloem sap reaching field pea seeds (Pisum sativum L.) be an accurate indicator of seed growth potential? Journal of Experimental Botany, 54: 2457-2465.

[53] Murphy, P. A. (2008). Soybean Proteins. Soybeans, 229-267. doi: 10.1016/b978-1-893997-64-6.50011-1.

[54] Ohyama, T., et al. (2017). Amino Acid Metabolism and Transport in Soybean Plants. Amino Acid - New Insights and Roles in Plant and Animal. Chapter 8: 171-196.

[55] Ohyama, T. et al (2017) Amino Acid Metabolism and Transport in Soybean Plants. Chapter 8 In Amino Acid - New Insights and Roles in Plant and Animal. doi: 10.5772/intechopen.68992

[56] Okumoto, S. and Pilot, G. (2011). Amino Acid Export in Plants: A Missing Link in Nitrogen Cycling. Molecular Plant, 4: 453-463. doi: $10.1093 / \mathrm{mp} / \mathrm{ssr} 003$

[57] Panda, B. B., Sekhar, S., Dash, S. K., Behera, L. andShaw, B. P. (2018). Biochemical and molecular characterisation of exogenous cytokinin application on grain filling in rice. BMC Plant Biology, 18: 89-107.

[58] Pfau, T., Christian, N., Masakapalli, S. K., Sweetlove, L. J., Poolman, M. G. and Ebenhöh, O. (2018). The intertwined metabolism during symbiotic nitrogen fixation elucidated by metabolic modelling. Scientific Reports, 8 (1). doi: 10.1038/s41598-018-30884-x

[59] Pichl, I. (1976). Amino Acid Composition and Nitrogen Content of Seed Albumins and Globulins of Various Species of the Cucurbitaceae Family. Biochemie Und Physiologie Der Pflanzen, 170: 509-515. 
[60] Rainbird, R. M., Thorne, J. H. and Hardy, R. W. F. (1984). Role of Amides, Amino Acids, and Ureides in the Nutrition of Developing Soybean Seeds. Pl. Physiol., 74 (2), 329-334.

[61] Rerie, W. G., Whitecross, M. and Higgins, T. J. V. Developmental and environmental regulation of pea legumin genes in transgenic tobacco.(1991). Molec. Gen. Genet. 225, 148-157. https://doi.org/10.1007/BF00282653

[62] Ricachenevsky, F. K., Vasconcelos, M. W., Shou, H., Johnson, A. A. T. and Sperotto, R. A. (2019). Editorial: Improving the Nutritional Content and Quality of Crops: Promises, Achievements, and Future Challenges. Frontiers in Plant Science, 10. Article 738-Editorial-1-4 P.

[63] Rao, A. S. (2001) Chloroplast genetic engineering. Trends Biotechnol. 19: 6.

[64] Rao, S. Adhikarla (2016). Conversion of C3 plants to C4 plants may lower the Rubisco amounts with negative effects on grain yield and protein concentration. J. Plant. Biochem. Biotechnol. (Springer) DOI 10.1007/s 13562-016-0379-9.

[65] Rao, A. S. and Randhir Singh (1983). Theoretical approaches for reducing bioenergetic costs and enhancing plant productivity. J. Theor. Biol. 104: 113-120.

[66] Rao, A. S. and Randhir Singh (1986). Improving grain protein quality by genetic engineering: some biochemical considerations. Trends Biotechnol, May 108-109.

[67] Rao, A. S. and Randhir Singh (1988). Ureide metabolism in nodulated egumes. In-Advances in frontier areas of plant biochemistry-Prentice -Hall of India, New Delhi, 281-316.

[68] Rao, A. S. (2019) eLetter, Science 21 March eaat9077Further appraisal of photorespiratory glycolate glycolate diversion. In response to Paul, F et al. 2019. Synthetic glycolate metabolism pathways stimulate crop growth and productivity in the field. $04^{\text {th }}$ Jan 2019363 : 96422) eaat9077

[69] Rentsch, D; Susanne Schmidt, S; and Tegeder, M. (2007). Transporters for uptake and allocation of organic nitrogen compounds in plants. FEBS Letters 581: 2281-2289.

[70] Schubert, K. R. (1986). Products of Biological Nitrogen Fixation in Higher Plants: Synthesis, Transport, and Metabolism. Annual Review of Plant Physiology, 37; 539-574.

[71] Sevindik, E. (2017). Amino Acids Sequence Based in Silico Analysis of RuBisCO (Ribulose-1,5 Bisphosphate Carboxylase Oxygenase) Proteins in Some Carthamus L. ssp. Notulae Scientia Biologicae, 9: 204-208.

[72] Shewry, P. R., Tatham, A. S. and Halford, N. G. (2001). Plant Growth Regulation, 34: 105-111.

[73] Shewry, P. R. (1995). Seed Storage Proteins: Structures and Biosynthesis. The Plant Cell Online, 7: 945-956.

[74] Shewry, P. R., \& Halford, N. G. (2002). Cereal seed storage proteins: structures, properties and role in grain utilization. Journal of Experimental Botany, 53: 947-958.

[75] Shitan, N. (2016). Secondary metabolites in plants: transport and self-tolerance mechanisms. Bioscience, Biotechnology, and Biochemistry, 80: 1283- 1293. doi: $10.1080 / 09168451.2016 .1151344$

[76] Simpson, R. J. and Dalling, M. J. (1981). Nitrogen Redistribution during Grain Growth in Wheat (Triticum aestivum L.): III. Planta, 151: 447-456.

[77] Simpson, R. J., Lambers, H. and Dalling, M. J. (1983). Nitrogen Redistribution during Grain Growth in Wheat (Triticum aestivum L.): IV. Development of a Quantitative Model of the Translocation of Nitrogen to the Grain. Pl. Physiol. 71: 7-14.

[78] Smith, C. R., Shekleton, M. C., Wolff, I. A. and Jones, Q. (1959). Seed protein sources-Amino acid composition and total protein content of various plant seeds. Economic Botany, 13: $132-150$.

[79] Takuji Ohyama, Norikuni Ohtake, Kuni Sueyoshi, Yuki Ono, Kotaro Tsutsumi, Manabu Ueno, Sayuri Tanabata, Takashi Sato and Yoshihiko Takahashi (2017). Amino Acid Metabolism and Transport in Soybean--New Insights and Roles in Plant and Animal. http://dx.doi.org/10.5772/intechopen.68992

[80] Taiz, Li. And Zeigler, E. (2010). Plant Physiology, $5^{\text {th }}$ Edition, Sin aver associates, Publishers, Inc.

[81] Tan, Q., Zhang, L., Grant., Cooper., and Tegeder, M. (2010). Increased phloem transport of S-methylmethionine positively affects sulfur and nitrogen metabolism and seed development in pea plants. Plant Physiol. 154: 1886-1896.

[82] Tegeder, M.(2014). Transporters involved in source to sink partitioning of amino acids and ureides: opportunities for crop improvement. J. Exp. Bot. 65: 1865-1878.

[83] Tegeder, M., \& Masclaux-Daubresse, C. (2017). Source and sink mechanisms of nitrogen transport and use. New Phytologist, 217 (1), 35-53. doi: 10.1111/nph.14876

[84] Tsai, C. Y., Huber, D. M. and Warren, H. L. (1980) A proposed role of zein and glutelin as $\mathrm{N}$ sinks in maize. Pl. Physiol. 66: 330-333.

[85] Unkovich, M., Baldock, J., \& Forbes, M. (2010). Variability in Harvest Index of Grain Crops and Potential Significance for Carbon Accounting. Advances in Agronomy, 173-219.

[86] VanEtten, C. H., Miller, R. W., Wolff, I. A., \& Jones, Q. (1963). Nutrients in Seeds, Amino Acid Composition of Seeds from 200 Angiospermous Plant Species. Journal of Agricultural and Food Chemistry, 11: 399-410.

[87] Van Dongen, J. T. (2004). Phloem Import and Storage Metabolism Are Highly Coordinated by the Low Oxygen Concentrations within Developing Wheat Seeds. Pl. Physiol., 135: 1809-1821.

[88] VanEtten C. H., Wolff I. A., Jones Q. and Miller R. W. (1963). Amino acid composition of seeds from 200 angiospermous plant species. J. Agric. Food Chem. 11, 399-410.

[89] Verdier, J. and Thompson, R. D. (2008). Transcriptional Regulation of Storage Protein Synthesis During Dicotyledon Seed Filling. Plant and Cell Physiology, 49: 1263-1271.

[90] Wang, T. L. Can we improve the nutritional quality of legume seeds ? P1. Physiol. 131: 886-891.

[91] Wink, M. (2010) Introduction: Biochemistry, Physiology and Ecological Functions of Secondary Metabolites. Biochemistry of Plant Secondary Metabolism, Annual Plant Reviews-40: 1-19. doi: 10.1002/9781444320503.ch1.

[92] Wang, T. L., Claire Domoney, C., Hedley, C. L. Rod Casey, and Grusak, M. A. (2003). Can We Improve the Nutritional Quality of Legume Seeds? Pl. Physiol. 131: 886-891. 
[93] Winter, G., Todd, C. D., Trovato, M., Forlani, G. and Funck, D. (2015). Physiological implications of arginine metabolism in plants. Frontiers in Plant Science, 6. Article 534.

[94] Wobus, U., 2003. Peptide and amino acid transporters are differentially regulated during seed development and germination in faba bean. Plant Physiol. 132, 1950-1960.

[95] Yaregal Damtie, Y. (2019). A Review of Improving The protein Quality with the Composition of Quality Traits of Maize (Zea mays L.) Grain and Possible Breeding Techniques. Asian journal of plant science and research, 9: 112.

[96] Yamagata, H., Sugimoto, T., Tanaka, K. and Kasai, Z. (1982) Biosynthesis of storage proteins in developing rice seeds. Pl. Physiol. 70: 1094-1100.
[97] Zhang, L., Garneau, M. G., Majumdar, R., Grant, J. and Tegeder, M. (2014). Improvement of pea biomass and seed productivity by simultaneous increase of phloem and embryo loading with amino acids. The Plant Journal, 81: 134-146.

[98] Zhang, N., Chen, F., Huo, W. and Cui, D. (2015). Proteomic analysis of middle and late stages of bread wheat (Triticum aestivum L.) grain development. Frontiers in Plant Science, 6. Article 735 doi: 10.3389/fpls.2015.00735

[99] Zheng, T. et al. (2018). Mechanisms of wheat (Triticum aestivum) grain storage proteins in response to nitrogen application and its impacts on processing quality. Scientific Reports, 8: 11928. 